\title{
Phentermine, Sibutramine and Affective Disorders
}

\author{
Hoyoung An ${ }^{1}$, Hyunjoo Sohn ${ }^{2}$, Seockhoon Chung ${ }^{3}$ \\ ${ }^{1}$ Department of Psychiatry, Jeju Medical Center, Jeju, ${ }^{2}$ Department of Family Medicine, Jeju National University School of Medicine, Jeju, \\ ${ }^{3}$ Department of Psychiatry, Asan Medical Center, University of Ulsan College of Medicine, Seoul, Korea
}

\begin{abstract}
A safe and effective way to control weight in patients with affective disorders is needed, and phentermine is a possible candidate. We performed a PubMed search of articles pertaining to phentermine, sibutramine, and affective disorders. We compared the studies of phentermine with those of sibutramine. The search yielded a small number of reports. Reports concerning phentermine and affective disorders reported that i) its potency in the central nervous system may be comparatively low, and ii) it may induce depression in some patients. We were unable to find more studies on the subject; thus, it is unclear presently whether phentermine use is safe in affective disorder patients. Reports regarding the association of sibutramine and affective disorders were slightly more abundant. A recent study that suggested that sibutramine may have deleterious effects in patients with a psychiatric history may provide a clue for future phentermine research. Three explanations are possible concerning the association between phentermine and affective disorders: i) phentermine, like sibutramine, may have a depression-inducing effect that affects a specific subgroup of patients, ii) phentermine may have a dose-dependent depression-inducing effect, or iii) phentermine may simply not be associated with depression. Large-scale studies with affective disorder patients focusing on these questions are needed to clarify this matter before investigation of its efficacy may be carried out and it can be used in patients with affective disorders.
\end{abstract}

KEY WORDS: Affect; Anti-obesity agents; Mood disorders; Obesity; Phentermine; Sibutramine.

\section{INTRODUCTION}

Weight gain is a common problem among affective disorder patients. ${ }^{1-6)}$ This propensity may partly be attributable to the disease itself, ${ }^{6)}$ and also to the various psychotropic medications used in its treatment, several of which have been associated with weight gain. ${ }^{4,6-8)}$ Furthermore, recent studies have found that obesity may be a predisposing factor for depression. ${ }^{9,10)}$ As increased weight is a common reason for poor compliance with treatment, ${ }^{11,12)}$ and higher body mass index has been associated with more severe disease in patients with bipolar I disorder and depression, ${ }^{1,6)}$ affective disorder patients would benefit greatly from safe and effective treatments for obesity. However, reports concerning anti-obesity treatments in patients with affective disorders are scarce.

In this article, we review the published data regarding

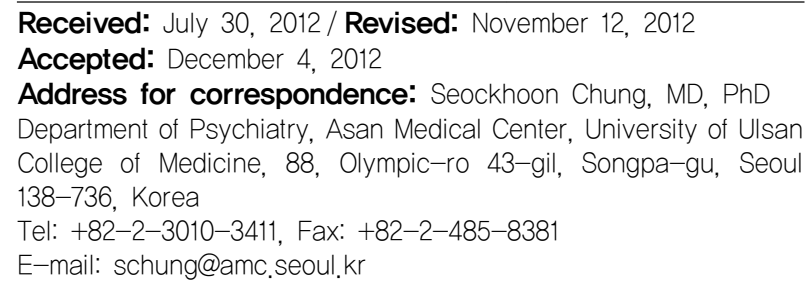

the association between phentermine and sibutramine, two well-known anti-obesity agents, and affective disorders. These drugs were chosen because both drugs have similar biological actions (modulation of noradrenergic, dopaminergic and serotonergic systems) and both are/were widely used (sibutramine has been withdrawn from the market). Published reports of phentermine will be examined first, and then, due to the paucity of relevant data, similar studies of sibutramine will be discussed. We believe these previous findings may suggest directions for future research.

\section{PHENTERMINE}

\section{Pharmacology}

Phentermine is a sympathomimetic amine structurally related to amphetamine. ${ }^{13)}$ Its main action is to stimulate noradrenergic signaling by promoting its release. At clinical doses, it also promotes dopamine (DA) and serotonin (5-hydroxytryptamine [5-HT]) release, although its actions on these two neurotransmitters are approximately 10 (DA) and 100 (5-HT) times weaker than its action on norepinephrine (NE). ${ }^{14)}$ It is thought that these actions increase sympathetic nervous system activity, thereby de-

(C) This is an Open-Access article distributed under the terms of the Creative Commons Attribution Non-Commercial License (http://creativecommons.org/licenses/by-nc/3.0) which permits unrestricted non-commercial use, distribution, and reproduction in any medium, provided the original work is properly cited. 
creasing food intake and increasing resting energy expenditure. $^{13)}$

A number of other amphetamine-related drugs, such as phendimetrazine, diethylpropion and mazindol, have also been marketed for the treatment of obesity. ${ }^{15,16)}$ Phendimetrazine and diethylpropion are structurally related to amphetamine, and have similar biological actions. Mazindol is structurally distinct from amphetamine and has a slightly different mechanism of action; however, it is also categorized as an amphetamine-related drug as its net effect is to increase NE signaling in central neurons. ${ }^{17)}$ Although all three drugs have been approved by the US Food and Drug Administration (FDA) for the short-term treatment of obesity, they are rarely used today; phendimetrazine, due to its high abuse potential, ${ }^{16)}$ diethylpropion, due to the scarcity of data supporting its efficacy, ${ }^{17)}$ and mazindol, due to its serious side effects. ${ }^{15)}$ Phentermine is the only amphetamine-related drug that is still widely used as an anti-obesity agent, ${ }^{13)}$ and therefore we will exclude the other three drugs from further discussion.

A recent biological study using a novel technique compared the potency of various DA and 5-HT releasers and reported that the potency of phentermine at the DA transporter was similar to that of methamphetamine and 3,4-methylenedioxymethamphetamine (MDMA). ${ }^{18)}$ This result was completely unexpected, because the potent action of both drugs on the DA system ${ }^{19,20)}$ has been linked several times to their high addictive potential, ${ }^{21,22)}$ indicating that phentermine may also be highly addictive. However, this does not seem to be the case. Previous reports have shown that phentermine is not associated with abuse or addiction potential, ${ }^{23)}$ and even that it decreases self-administration of cocaine in rats when administered with fluoxetine. ${ }^{24)}$ The answer to this discrepancy may lie in the inability of phentermine to act in the central nervous system (CNS). Alexander et al. ${ }^{25)}$ compared the amount of central DA release in baboons via positron emission tomography after injecting them with amphetamine, phentermine and ephedrine, and reported that only amphetamine was able to release DA from CNS neurons and decrease plasma prolactin. Thus, this result may suggest that the low or absent addiction potential of phentermine is, in part, due to its low activity in the CNS. However, as methamphetamine and MDMA were not used, drawing a definite conclusion from this result is not possible, and a direct comparison is needed. Furthermore, whether phentermine is also unable to increase central NE, and, if that is so, how phentermine decreases appetite without acting in the
CNS, are also topics for future studies.

\section{Association with Affective Disorders}

The actions of phentermine are similar to those of bupropion, a widely used antidepressant, in that both increase synaptic NE and DA levels. ${ }^{26)}$ Additionally, the prescription information for Adipex- $\mathrm{P}^{\circledR}$ (Teva Pharmaceuticals USA, Sellersville, PA, USA) also includes euphoria and dysphoria as possible adverse effects. ${ }^{27)}$ Consequently, phentermine may affect mood. However, our search concerning this association yielded only four case reports and two studies.

Of the four case reports, three involved manic-like episodes. One reported that combination treatment with phentermine and fenfluramine induced psychotic mania in a patient with major depressive disorder. ${ }^{28)}$ Another report described a depressive patient with a sudden onset of restlessness and flight of ideas after treatment with fluoxetine and phentermine. ${ }^{29)}$ The third report was a case in which phentermine induced a manic episode in a patient with no previous psychiatric history, but who had a strong family history of affective disorder. ${ }^{30)}$ Finally, Zimmer and Gregory ${ }^{31)}$ reported a case of bipolar depression associated with phentermine and fenfluramine treatment, in a patient with pre-existing bipolar I disorder.

We were unable to find any reported study associated with phentermine examining mood symptoms as a primary outcome; we believe the reports of mood-related adverse effects from phase III trials ${ }^{27)}$ may have discouraged further investigation. The two studies we did find reported findings related to mood symptoms as secondary outcomes. In an older study, researchers administered phentermine to 50 women with refractory obesity. ${ }^{32)}$ Seven withdrew due to adverse effects, one due to depressive symptoms and one due to breathlessness, palpitations, and irritability. The more recent study was a randomized controlled trial seeking to evaluate the safety and efficacy of a recently approved controlled-release combination of phentermine and topiramate. ${ }^{33,34)}$ In total, 1,267 subjects were randomized to receive a placebo, a low-dose combination or a high-dose combination for 56 weeks. The primary outcome was weight loss. Mean depressive symptoms, assessed via the Patient Health Questionnaire-9, showed improvements in all three groups over time, and there was no significant difference between treatment groups. However, the number of subjects who withdrew due to depression was significantly higher in the high-dose group vs. the placebo group (4.7\% vs. $1.2 \%$; $p<0.001)$. Although the overall incidence was not high, 
because subjects with a documented history of major depressive episodes or current depressive episode of moderate or higher severity were excluded, the question as to whether this medication is safe in patients with affective disorders remains unanswered. Also, considering recent reports of topiramate-related CNS adverse-effects, ${ }^{35)}$ the depressive symptoms may have been caused by topiramate and not phentermine.

Based on these findings, three explanations are possible: $i)$ phentermine has a prodepressive effect that affects a specific subgroup of patients, $i$ i) phentermine has a prodepressive effect and it is dose-dependent, or iii) phentermine is not associated with depression and the depressive symptoms were caused by topiramate. Further studies are needed to assess which of these explanations is correct, or if another explanation exists.

\section{SIBUTRAMINE}

\section{Pharmacology}

Sibutramine is a potent monoamine reuptake inhibitor, selective for NE and 5-HT. ${ }^{36)}$ Its actions are mediated through its active metabolites, which have potencies comparable to the NE reuptake inhibitor desipramine and the 5-HT reuptake inhibitor fluoxetine. ${ }^{36)}$ It also inhibits DA reuptake, although its potency at this site is comparatively weaker. Sibutramine decreases food intake by enhancing satiety ${ }^{37)}$ and also increases the metabolic rate and thermogenesis. ${ }^{38)}$ It was a widely used anti-obesity agent before its withdrawal due to concerns about increased cardiovascular events. ${ }^{39)}$

\section{Association with Affective Disorders}

The actions of sibutramine are similar to those of serotonin-NE reuptake inhibitors, such as venlafaxine or duloxetine, which are used widely as antidepressants. ${ }^{40)}$ For this reason, it might be surmised that sibutramine influences affect, possibly similarly to the antidepressants mentioned before. However, there have been several studies and case reports with conflicting results suggesting that the association between sibutramine and mood may not be quite so simple.

Of the four case reports found, only one concerned a de novo mood episode. ${ }^{41)}$ The other three reported manic or hypomanic episodes in patients with a histories of bipolar disorder. $^{42-44)}$

Due to its much wider use, studies of sibutramine were more common than those of phentermine. Four studies reported outcomes related to affective symptoms. In two, mean depressive symptoms decreased following the administration of sibutramine. ${ }^{45,46)}$ The first study investigated mood- and weight-related change in initial eating behavior. ${ }^{45)}$ In total, 36 subjects were given sibutramine for six months. Depressive symptoms, assessed with the Comprehensive Psychopathological Rating Scale, decreased significantly at the study endpoint compared with baseline values, and this decrease was not associated with weight loss. In a more recent study, 60 obese and overweight women were divided into three groups and received a low-calorie diet and sibutramine, a low-calorie diet and orlistat, or a low-calorie diet alone. ${ }^{46)}$ Depressive symptoms, as assessed by the Hamilton Depression Rating Scale (HAM-D), decreased in all three groups. The decrease in HAM-D scores in the sibutramine group was significantly greater than the other groups (from 12.0 to 7.2 in the sibutramine group, from 11.4 to 9.8 in the low-calorie diet group and from 11.0 to 9.2 in the orlistat group; $p<0.01$ ). These two studies suggest that sibutramine may have an antidepressant effect.

On the other hand, there are also reports showing that sibutramine may induce depression. The FDA drug label for sibutramine contains information concerning increased adverse events of depression in subjects taking sibutramine, compared with subjects taking placebo. ${ }^{47)}$ Moreover, we found two reports with similar results. ${ }^{48,49)}$ In a study in England, the authors used a cohort monitoring technique ${ }^{50)}$ to investigate the safety profiles of sibutramine and orlistat. ${ }^{48)}$ Patients who were prescribed with either sibutramine $(n=12,336)$ or orlistat $(n=16,021)$ were monitored and patient information, including reasons for discontinuation, was assessed via questionnaires sent to the general practitioners who had prescribed the medications. Of a cohort of 28,357 subjects, 4,854 (30.3\%) from the orlistat group and 5,155 (41.8\%) from the sibutramine group were reported to have discontinued their medication within three months of starting treatment. In the sibutramine group, 94 subjects $(0.8 \%)$ had discontinued due to adverse effects related to depression; it was the fifth most frequent reason for discontinuation. In another study, researchers randomized 46 subjects with a history of bipolar I or II disorder, or schizoaffective disorder, bipolar type, into two groups. ${ }^{49)}$ Each group received either sibutramine or topiramate for 24 weeks, and weight loss was compared between the groups. The results showed that both medications were effective at reducing weight and that their efficacies were similar. The interesting point was the high drop-out rate. Only 10 subjects completed the trial; 14 subjects from the sibutramine group (78\% of 
group) and 22 from the topiramate group (79\% of group) were unable to complete the study. Six subjects (33\% of group) from the sibutramine group withdrew due to worsening of mood: two due to depression, two due to mania, and one due to cycle acceleration. Specific details of the worsened mood were not reported for one subject.

A recent study suggested a possible explanation for these contradictory findings. Faulconbridge $e t$ al. ${ }^{51)}$ followed a cohort of 194 obese subjects that were randomized into four groups: i) sibutramine alone, ii) lifestyle modification alone, iii) sibutramine and lifestyle modification, and iv) sibutramine and brief therapy. The trial duration was one year and depressive symptoms were assessed using the Beck Depression Inventory (BDI)-II. Although mean BDI-II scores decreased significantly in all four groups, $13.9 \%$ of the cohort reported potentially discernible increases (increase of $\geq 5$ points on the BDI-II) at the end of the study. Subgroup analysis revealed that $44.4 \%$ of these subjects had a history of psychiatric disorders, compared with only $26.9 \%$ of the subjects who did not experience worsening of depressive symptoms $(p<0.05)$. These subjects also lost significantly less weight compared with the rest of the study subjects. Thus, as the authors discussed, the increase in depressive scores may have been due to disappointment due to the smaller loss in weight. Alternatively, these results also suggest that while sibutramine was beneficial to most of the population, it may have deleterious effects on individuals with a psychiatric history. Reaching a definitive conclusion is currently not possible, because the psychiatric history was based solely on self-reports and subjects with clinically significant psychiatric conditions were excluded from the study. Further examination is impossible because sibutramine has been withdrawn from the market.

\section{DISCUSSION}

A safe and effective way to control weight in patients with affective disorders is needed, because a substantial number of these patients suffer from obesity. Phentermine is a possible candidate, as it is one of the most widely used anti-obesity agents today. ${ }^{13)}$ However, before it can be used in this population, two questions need to be answered: is it safe and does it work?

Based on the reports reviewed, it seems that phentermine may have the potential for increased neuropsychiatric adverse events, including affective symptoms. Case reports indicated that the use of phentermine in patients with bipolar disorder may lead to manic or hypomanic epi- sodes, ${ }^{28-31)}$ and the report of Allison et al. ${ }^{33)}$ suggested that phentermine may induce or aggravate depression in some patients. However, an animal study showed that this may not be true ${ }^{25)}$ and we were unable to find any relevant reports concerning large-scale studies. Further studies will be needed to clarify this matter. Similar studies examining the potency of phentermine in the CNS on NE and 5-HT transport would be very helpful in creating a more detailed picture of its biological actions, and a large-scale study focusing on its neuropsychiatric adverse effects would answer several issues related to its safety.

The studies of sibutramine provide clues for future phentermine research. As reviewed beforehand, studies concerning the safety of sibutramine use in affective disorder patients showed contradictory results. Some studies showed it was safe and effective, ${ }^{45,46)}$ whereas others showed that it was sometimes associated with worsening depression. ${ }^{48,49)}$ A later study revealed that this inconsistency may have been due to patient factors. ${ }^{51)}$ As shown in the results, patients who experienced increased levels of depressive symptoms were more likely to have a history of psychiatric illness.

These findings raise a pertinent question: do certain patient factors connect phentermine use with depression, as with sibutramine? The factors may be a history of psychiatric illness, or more specifically, a history of bipolar disorder or depression. A positive family history may also be sufficient. Or, if this is not the case, is the depression-inducing effect of phentermine dose-dependent? Is there another explanation for these findings? Large-scale studies with affective disorder patients focusing on these questions will be needed to clarify this matter before investigation of the drug's efficacy may be carried out, and it can be used to reduce suffering in patients with affective disorders.

\section{FUTURE CONSIDERATIONS}

Several promising new pharmacologic agents have been recently approved or are in the last stages of development. They include the aforementioned phentermine-topiramate combination, lorcaserin, and a bupropion-naltrexone combination.

The phentermine-topiramate combination was approved for use in the short-term treatment of obesity in $2012{ }^{34)}$ Topiramate is a widely used anticonvulsant that was once considered a candidate for monotherapy in anti-obesity treatment until studies revealed that its use under this indication was associated with unacceptable ad- 
verse-effects. ${ }^{52-54)}$ Combining it with phentermine proved to be more safer and effective than using either drug alone, and several studies have shown that its efficacy may be greater than previously used drugs. ${ }^{52)}$ However, as previous studies have shown that it may be associated with an increased risk of depression, ${ }^{33)}$ further studies focusing on subjects with affective disorders will be needed until it can be used safely in this group of patients.

Lorcaserin, a $5-\mathrm{HT}_{2 \mathrm{C}}$ agonist, is another anti-obesity drug that has been recently approved by the FDA. ${ }^{55)}$ Related studies have indicated that although it is clinically effective in reducing body weight, its efficacy may be inferior to previously used medications such as sibutramine. ${ }^{52)}$ We were unable to find any reports regarding its use in patients with affective disorders.

The bupropion-naltrexone combination has also been studied extensively, including a number of phase III trials. Bupropion is an NE-DA reuptake inhibitor that is used in the treatment of smoking cessation and depression. ${ }^{56)}$ Naltrexone is a non-selective opioid receptor antagonist used in the treatment of alcohol and opiate dependence. ${ }^{56)}$ Although it has shown a significant weight-reducing effect in a number of trials, the FDA has not approved it yet due to concerns of cardiovascular adverse events. ${ }^{52)} \mathrm{We}$ were also unable to find any reports of its use in patients with affective disorders. However, there have been several studies concerning each individual drug in an affective disorder study group, with results showing that the use of either drug may be considered safe. ${ }^{57-59)}$

All of the pharmacological agents mentioned above have shown promise as an anti-obesity drug. However, we do not yet know if they can be used safely in affective disorder patients. If they are proved to be safe, then they may someday be considered a major adjunctive agent in the treatment of bipolar disorder.

\section{REFERENCES}

1. Berkowitz RI, Fabricatore AN. Obesity, psychiatric status, and psychiatric medications. Psychiatr Clin North Am 2011; 34:747-764.

2. de Wit L, Luppino F, van Straten A, Penninx B, Zitman F, Cuijpers P. Depression and obesity: a meta-analysis of community-based studies. Psychiatry Res 2010;178:230-235.

3. Fagiolini A, Frank E, Houck PR, Mallinger AG, Swartz HA, Buysse DJ, et al. Prevalence of obesity and weight change during treatment in patients with bipolar I disorder. J Clin Psychiatry 2002;63:528-533.

4. Keck PE, McElroy SL. Bipolar disorder, obesity, and pharmacotherapy-associated weight gain. J Clin Psychiatry 2003; 64:1426-1435.

5. McElroy SL, Frye MA, Suppes T, Dhavale D, Keck PE Jr, Leverich GS, et al. Correlates of overweight and obesity in 644 patients with bipolar disorder. J Clin Psychiatry 2002;
63:207-213.

6. McElroy SL, Kotwal R, Malhotra S, Nelson EB, Keck PE, Nemeroff CB. Are mood disorders and obesity related? A review for the mental health professional. J Clin Psychiatry 2004;65:634-651.

7. Hirschfeld RM. Long-term side effects of SSRIs: sexual dysfunction and weight gain. J Clin Psychiatry 2003;64(Suppl 18):20-24.

8. McIntyre RS, McCann SM, Kennedy SH. Antipsychotic metabolic effects: weight gain, diabetes mellitus, and lipid abnormalities. Can J Psychiatry 2001;46:273-281.

9. Nathan PJ, O'Neill BV, Napolitano A, Bullmore ET. Neuropsychiatric adverse effects of centrally acting antiobesity drugs. CNS Neurosci Ther 2011;17:490-505.

10. Dixon JB, Dixon ME, O'Brien PE. Depression in association with severe obesity: changes with weight loss. Arch Intern Med 2003;163:2058-2065.

11. Fakhoury WK, Wright D, Wallace M. Prevalence and extent of distress of adverse effects of antipsychotics among callers to a United Kingdom National Mental Health Helpline. Int Clin Psychopharmacol 2001;16:153-162.

12. Gitlin MJ, Cochran SD, Jamison KR. Maintenance lithium treatment: side effects and compliance. J Clin Psychiatry 1989;50:127-131.

13. Kaplan LM. Pharmacologic therapies for obesity. Gastroenterol Clin North Am 2010;39:69-79.

14. Rothman RB, Baumann MH, Dersch CM, Romero DV, Rice $\mathrm{KC}$, Carroll FI, et al. Amphetamine-type central nervous system stimulants release norepinephrine more potently than they release dopamine and serotonin. Synapse 2001;39:3241.

15. Ioannides-Demos LL, Proietto J, McNeil JJ. Pharmacotherapy for obesity. Drugs 2005;65:1391-1418.

16. Greenway FL, Caruso MK. Safety of obesity drugs. Expert Opin Drug Saf 2005;4:1083-1095.

17. Ioannides-Demos LL, Piccenna L, McNeil JJ. Pharmacotherapies for obesity: past, current, and future therapies. $J$ Obes 2011;2011:179674.

18. John CE, Jones SR. Voltammetric characterization of the effect of monoamine uptake inhibitors and releasers on dopamine and serotonin uptake in mouse caudate-putamen and substantia nigra slices. Neuropharmacology 2007;52: 1596-1605.

19. Franken IH, Booij J, van den Brink W. The role of dopamine in human addiction: from reward to motivated attention. Eur J Pharmacol 2005;526:199-206.

20. Taber KH, Black DN, Porrino LJ, Hurley RA. Neuroanatomy of dopamine: reward and addiction. J Neuropsychiatry Clin Neurosci 2012;24:1-4.

21. Cruickshank CC, Dyer KR. A review of the clinical pharmacology of methamphetamine. Addiction 2009;104:10851099.

22. Nakagawa T, Kaneko S. Neuropsychotoxicity of abused drugs: molecular and neural mechanisms of neuropsychotoxicity induced by methamphetamine, 3,4-methylenedioxymethamphetamine (ecstasy), and 5-methoxy- $N, N$-diisopropyltryptamine (foxy). J Pharmacol Sci 2008;106:2-8.

23. Hendricks EJ, Greenway FL. A study of abrupt phentermine cessation in patients in a weight management program. Am $J$ Ther 2011;18:292-299.

24. Glatz AC, Ehrlich M, Bae RS, Clarke MJ, Quinlan PA, Brown EC, et al. Inhibition of cocaine self-administration by fluoxetine or D-fenfluramine combined with phentermine. Pharmacol Biochem Behav 2002;71:197-204.

25. Alexander M, Rothman RB, Baumann MH, Endres CJ, 
Brasic JR, Wong DF. Noradrenergic and dopaminergic effects of $(+)$-amphetamine-like stimulants in the baboon Papio anubis. Synapse 2005;56:94-99.

26. Moreira R. The efficacy and tolerability of bupropion in the treatment of major depressive disorder. Clin Drug Investig 2011;31(Suppl 1):5-17.

27. Teva Pharmaceuticals USA. Adipex-P drug label. 2012 [cited 2012 Jul 1]. Available from http://www.adipex.com/ contents/pdf/Adipex_pi.pdf.

28. Raison CL, Klein HM. Psychotic mania associated with fenfluramine and phentermine use. Am J Psychiatry 1997; 154:711.

29. Bostwick JM, Brown TM. A toxic reaction from combining fluoxetine and phentermine. J Clin Psychopharmacol 1996; 16:189-190.

30. Cleare AJ. Phentermine, psychosis, and family history. $J$ Clin Psychopharmacol 1996;16:470-471.

31. Zimmer JE, Gregory RJ. Bipolar depression associated with fenfluramine and phentermine. J Clin Psychiatry 1998;59: 383-384.

32. Douglas A, Douglas JG, Robertson CE, Munro JF. Plasma phentermine levels, weight loss and side-effects. Int $J$ Obes 1983; 7:591-595.

33. Allison DB, Gadde KM, Garvey WT, Peterson CA, Schwiers $\mathrm{ML}$, Najarian T, et al. Controlled-release phentermine/topiramate in severely obese adults: a randomized controlled trial (EQUIP). Obesity (Silver Spring) 2012;20:330-342.

34. Food and Drug Administration. Qsymia (phentermine and topiramate extended-release) capsules approval letter 2012. 2012 [cited 2012 Jul 1]. Available from: http://www.accessdata. fda.gov/scripts/cder/drugsatfda/index.cfm?fuseaction=Search. Label_ApprovalHistory\#apphist.

35. Rosenstock J, Hollander P, Gadde KM, Sun X, Strauss R, Leung A; OBD-202 Study Group. A randomized, doubleblind, placebo-controlled, multicenter study to assess the efficacy and safety of topiramate controlled release in the treatment of obese type 2 diabetic patients. Diabetes Care 2007;30:1480-1486.

36. Nisoli E, Carruba MO. An assessment of the safety and efficacy of sibutramine, an anti-obesity drug with a novel mechanism of action. Obes Rev 2000;1:127-139.

37. Halford JC, Wanninayake SC, Blundell JE. Behavioral satiety sequence (BSS) for the diagnosis of drug action on food intake. Pharmacol Biochem Behav 1998;61:159-168.

38. Connoley IP, Liu YL, Frost I, Reckless IP, Heal DJ, Stock MJ. Thermogenic effects of sibutramine and its metabolites. Br J Pharmacol 1999;126:1487-1495.

39. Food and Drug Administration. FDA Drug Safety Coтmunication: FDA recommends against the continued use of Meridia (sibutramine) 2010. Available from: http://www.fda. gov/Drugs/DrugSafety/ucm228746.htm.

40. Bymaster FP, Dreshfield-Ahmad LJ, Threlkeld PG, Shaw JL, Thompson L, Nelson DL, et al. Comparative affinity of duloxetine and venlafaxine for serotonin and norepinephrine transporters in vitro and in vivo, human serotonin receptor subtypes, and other neuronal receptors. Neuropsychopharmacology 2001;25:871-880.

41. Naik S, Khoo CL, Lua R, Chai SB, Liew A, Sim K. Recurrent episodes of brief affective psychosis induced by sibutramine. Prog Neuropsychopharmacol Biol Psychiatry 2010;34:1359-1360.

42. Cordeiro Q, Vallada H. Sibutramine-induced mania episode in a bipolar patient. Int J Neuropsychopharmacol 2002;5: 283-284.
43. Benazzi F. Organic hypomania secondary to sibutraminecitalopram interaction. J Clin Psychiatry 2002;63:165.

44. Rocha FF, Bamberg TO, Pinto FC, Gomes LM, Silveira S. Hypomanic episode secondary to sibutramine in a patient with type-I bipolar disorder. Rev Bras Psiquiatr 2008;30: 400-401.

45. Elfhag K, Rössner S, Barkeling B, Rooth P. Sibutramine treatment in obesity: initial eating behaviour in relation to weight loss results and changes in mood. Pharmacol Res 2005;51:159-163.

46. Kiortsis DN, Tsouli S, Filippatos TD, Konitsiotis S, Elisaf MS. Effects of sibutramine and orlistat on mood in obese and overweight subjects: a randomised study. Nutr Metab Cardiovasc Dis 2008;18:207-210.

47. Abott Laboratories. Sibutramine drug label 2010. 2010 [cited 2012 Jul 1]. Available from: http://www.accessdata.fda.gov/ drugsatfda_docs/label/2010/020632s034s035lbl.pdf.

48. Perrio MJ, Wilton LV, Shakir SA. The safety profiles of orlistat and sibutramine: results of prescription-event monitoring studies in England. Obesity (Silver Spring) 2007;15: 2712-2722.

49. McElroy SL, Frye MA, Altshuler LL, Suppes T, Hellemann $\mathrm{G}$, Black D, et al. A 24-week, randomized, controlled trial of adjunctive sibutramine versus topiramate in the treatment of weight gain in overweight or obese patients with bipolar disorders. Bipolar Disord 2007;9:426-434.

50. Shakir SAW. Prescription-event monitoring. In: Strom BL, editor. Textbook of pharmacoepidemiology. 4th ed. Chichester: John Wiley \& Sons;2005. p.203-216.

51. Faulconbridge LF, Wadden TA, Berkowitz RI, Sarwer DB, Womble LG, Hesson LA, et al. Changes in symptoms of depression with weight loss: results of a randomized trial. Obesity (Silver Spring) 2009;17:1009-1016.

52. Heal DJ, Gosden J, Smith SL. What is the prognosis for new centrally-acting anti-obesity drugs? Neuropharmacology 2012:63:132-146.

53. Astrup A, Toubro S. Topiramate: a new potential pharmacological treatment for obesity. Obes Res 2004;12(Suppl): 167S-173S.

54. Eliasson B, Gudbjörnsdottir S, Cederholm J, Liang Y, Vercruysse F, Smith U. Weight loss and metabolic effects of topiramate in overweight and obese type 2 diabetic patients: randomized double-blind placebo-controlled trial. Int J Obes (Lond) 2007;31:1140-1147.

55. Food and Drug Administration. Belviq (lorcaserin hydrochloride) approval letter 2012. 2012 [cited 2012 Jul 1] Available from: http://www.accessdata.fda.gov/scripts/cder/drugsatfda/ index.cfm?fuseaction=Search.Label_ApprovalHistory\#apphist.

56. Stahl SM. Stahl's essential psychopharmacology: The prescriber's guide. 4th ed. Cambridge: Cambridge University Press; 2011.

57. Sachs GS, Lafer B, Stoll AL, Banov M, Thibault AB, Tohen $\mathrm{M}$, et al. A double-blind trial of bupropion versus desipramine for bipolar depression. J Clin Psychiatry 1994;55:391393.

58. Parikh SV, LeBlanc SR, Ovanessian MM. Advancing bipolar disorder: key lessons from the Systematic Treatment Enhancement Program for Bipolar Disorder (STEP-BD). Can J Psychiatry 2010;55:136-143

59. Brown ES, Carmody TJ, Schmitz JM, Caetano R, Adinoff $\mathrm{B}$, Swann AC, et al. A randomized, double-blind, placebocontrolled pilot study of naltrexone in outpatients with bipolar disorder and alcohol dependence. Alcohol Clin Exp Res 2009;33:1863-1869. 